\title{
Platelet transfusion in pregnancy: clinical profile and pregnancy outcome
}

\author{
Ritu Khatuja ${ }^{1}$, Geetika Jain ${ }^{1}$, Gita Radhakrishnan ${ }^{1}$, Anshul Grover ${ }^{1}$, Bharat Singh ${ }^{2}$ \\ ${ }^{1}$ Department of Obstetrics and Gynaecology, ${ }^{2}$ Department of Blood Bank, UCMS and GTB hospital, Dilshad Garden, \\ Delhi, India
}

Received: 27 April 2016

Accepted: 02 June 2016

\author{
*Correspondence: \\ Dr. Ritu Khatuja, \\ E-mail: drritu.kj@gmail.com
}

Copyright: ( $\odot$ the author(s), publisher and licensee Medip Academy. This is an open-access article distributed under the terms of the Creative Commons Attribution Non-Commercial License, which permits unrestricted non-commercial use, distribution, and reproduction in any medium, provided the original work is properly cited.

\begin{abstract}
Background: Thrombocytopenia, being second important hematological disorder of pregnancy can result in maternal and neonatal morbidity and mortality in some women. Some of these disorders are not associated with adverse pregnancy outcomes while in others it is associated with maternal and neonatal morbidity and mortality. So this study was conducted to evaluate the various causes of thrombocytopenia associated with platelet transfusion and its effect on maternal and neonatal outcome.

Methods: It is a retrospective data analysis of 70 peripartum women admitted in a tertiary level hospital with thrombocytopenia, requiring platelet transfusion over a period of 9 months (January 2013 to September 2013). Patients were analyzed for the cause of thrombocytopenia, requirement of platelet transfusion, additional treatment, duration of hospital stay and maternal and neonatal morbidity and mortality.

Results: In this study, pre-eclampsia and HELLP was present in $37.1 \%(n=26)$ of women requiring platelet transfusion while obstetrical hemorrhage (APH, PPH and Rupture uterus), combined iron deficiency anemia and infective causes accounted for $27.1 \%(\mathrm{n}=19), 17.1 \%(\mathrm{n}=12)$ and $15.7 \%(\mathrm{n}=11)$ of women respectively. One case each of APLA and idiopathic thrombocytopenia was seen. $70 \%$ of women had to stay in hospital for more than 5 days. Four women expired and the incidence of morbidities was $73.1 \%$. Prematurity was present in $41.1 \%$ neonates and three expired in nursery. Neonatal morbidity and mortality was not affected by maternal thrombocytopenia.

Conclusions: Thrombocytopenia associated with pathological conditions like HELLP, dengue and malaria were associated with profound maternal and neonatal morbidity.
\end{abstract}

Keywords: Thrombocytopenia, Platelet transfusion, Maternal outcome, Neonatal outcome

\section{INTRODUCTION}

Thrombocytopenia in pregnancy is one of the important hematological disorders other than anemia. Thrombocytopenia affects $6 \%$ to $10 \%$ of all pregnant women. ${ }^{1}$ It is defined as a platelet count of less than 1.5 lac/milliliter. ${ }^{2}$ This may result from a number of diverse etiologies. While some of these are not associated with adverse pregnancy outcomes, others are associated with maternal and neonatal morbidity and mortality which may lead to platelet transfusion in these patients. Thus, this study was conducted to find out the various causes of thrombocytopenia requiring platelet transfusion and its effect on maternal and neonatal outcome.

\section{METHODS}

This is a retrospective analysis of 70 peripartum women with thrombocytopenia requiring platelet transfusion. The study was conducted over a period of 9 months (January 2013 to September 2013) in a tertiary level hospital in East Delhi, India. All patients admitted in obstetrical 
emergency unit during peripartum period requiring platelet transfusion were included in the study. The clinical details of all women were collected by reviewing their hospital as well as their perinatal records.

\section{RESULTS}

During the study period of 9 months, a total of 7983 deliveries were conducted, of which 884 patients (11.2\%) had thrombocytopenia. Records revealed that 70 women received platelet transfusion during this period.

Table 1: Demographic and obstetric profile.

\begin{tabular}{|c|c|c|}
\hline Parameters & $\begin{array}{l}\text { Number of } \\
\text { women }(n=70)\end{array}$ & Percentage $(\%)$ \\
\hline \multicolumn{3}{|c|}{ Maternal age (years) } \\
\hline $20-25$ & 35 & $50 \%$ \\
\hline $26-30$ & 25 & $35.7 \%$ \\
\hline $31-35$ & 9 & $12.85 \%$ \\
\hline$>35$ & 1 & $1.42 \%$ \\
\hline \multicolumn{3}{|c|}{ Parity of patients } \\
\hline Primigravida & 19 & $27.1 \%$ \\
\hline $2^{\text {nd }}-4^{\text {th }}$ gravid & 38 & $54.28 \%$ \\
\hline$>4^{\text {th }}$ gravid & 4 & $5.7 \%$ \\
\hline \multicolumn{3}{|c|}{ Period of gestation age (weeks) } \\
\hline$<37$ & 38 & $54.28 \%$ \\
\hline $37-39$ & 17 & $24.28 \%$ \\
\hline$>39$ Weeks & 6 & $8.57 \%$ \\
\hline Postpartum & 9 & $12.85 \%$ \\
\hline \multicolumn{3}{|c|}{ Severity of thrombocytopenia } \\
\hline Mild & 5 & $7.14 \%$ \\
\hline Moderate & 24 & $34.28 \%$ \\
\hline Severe & 41 & $58.57 \%$ \\
\hline
\end{tabular}

All women belonged to low socio-economic strata. As depicted in table 1 , the mean age of the patients were 25.2 years and majority were multiparous $(n=42)$. In this study, 61 antepartum women carrying singleton fetus presented with thrombocytopenia of which, 38 women were less than 37 weeks of gestation and nine were postpartum women. Severe thrombocytopenia (platelet count below 50,000) was found in 41 women, moderate thrombocytopenia (50,000 to one lacs) in 24 and five had mild thrombocytopenia (one lac to 1.5 lacs).

The main etiology of thrombocytopenia requiring platelet transfusion was preeclampsia and HELLP Syndrome $(n=26)$. It is seen that in 12 women anemia was found to be associated with thrombocytopenia and 11 had an underline infectious cause. Obstetrical haemorrhage in form of ante-partum haemorrhage (APH), postpartum haemorrhage (PPH) and rupture uterus are found in 19 women. In this study, only one woman with Antiphosholipid antibody syndrome (APLA) and a single case of idiopathic thrombocytopenic purpura (ITP) as the etiology for thrombocytopenia was present. Both of them required platelet transfusion due to associated obstetrical hemorrhage (Table 2).

Table 2: Etiology of platelet transfusion.

\begin{tabular}{|lll|}
\hline $\begin{array}{l}\text { Etiology of platelet } \\
\text { transfusion }\end{array}$ & $\begin{array}{l}\text { Number of } \\
\text { women }(\mathbf{n = 7 0})\end{array}$ & $\begin{array}{l}\text { Percentage } \\
(\%)\end{array}$ \\
\hline $\begin{array}{l}\text { Hypertensive } \\
\text { disorder of pregnancy }\end{array}$ & 26 & $37.1 \%$ \\
\hline Anemia & 12 & $17.1 \%$ \\
\hline Infection & 11 & $15.7 \%$ \\
\hline APH & 8 & $11.4 \%$ \\
\hline Rupture uterus & 6 & $8.57 \%$ \\
\hline PPH & 5 & $7.14 \%$ \\
\hline APLA & 1 & $1.4 \%$ \\
\hline ITP & 1 & $1.4 \%$ \\
\hline
\end{tabular}

The maximum duration of hospital stay was 35 days with the mean duration being 6.1 days where as in $70 \%(n=49)$ women the duration of stay in hospital was more than 5 days. There were 4 patients $(5.7 \%)$ who expired during the study period of which 3 had severe thrombocytopenia and one had moderate thrombocytopenia. Intensive critical care was required in 11 women and 6 subjects were shifted to medicine unit in view of underline medical disorder or developed medical complications. The incidence of morbidity was as high as $73.1 \%$ in form of acute renal failure, lung infections, wound dehiscence, ICU admissions, operative interventions and paresis. There were operative intervention in 35 women form of caesarean section $(n=29)$ and hysterectomy (Table 3$)$.

Table 3: Maternal and Fetal outcome.

\begin{tabular}{|lcc|}
\hline $\begin{array}{l}\text { Maternal outcome } \\
\text { women }(\mathrm{n}=70)\end{array}$ & $\begin{array}{c}\text { Number of } \\
(\%)\end{array}$ \\
\hline $\begin{array}{l}\text { Obstetrical hysterectomy } \\
\text { (postpartum+cesearean) }\end{array}$ & 6 & $8.57 \%$ \\
\hline ICU care & 11 & $15.7 \%$ \\
\hline Wound infection & 15 & $21.42 \%$ \\
\hline Acute renal failure & 4 & $5.71 \%$ \\
\hline Lung infection & 5 & $7.14 \%$ \\
\hline Paresis & 1 & $1.4 \%$ \\
\hline Neonatal outcome & Number of & $\begin{array}{l}\text { Percentage } \\
(\%)\end{array}$ \\
\hline Live birth & 57 & $81.42 \%$ \\
\hline IUD & 13 & $18.57 \%$ \\
\hline Low birth weight & 29 & $41.42 \%$ \\
\hline NICU admission & 19 & $27.14 \%$ \\
\hline
\end{tabular}

The prevalence of low birth weight in babies born to mothers with thrombocytopenia was $41.4 \% \quad(n=29)$ in study group. Such a high rate can be attributed to preterm induction and associated obstetrical complications requiring preterm intervention. There were 13 intrauterine deaths. Babies requiring nursery care were $27.1 \%(n=19)$ of which maximum stay there was 10 days. 
Three babies expired in nursery due to low birth weight and septicemia (Table 3).

\section{DISCUSSION}

The present study was aimed to evaluate physiological and pathological causes of thrombocytopenia in pregnancy which lead to platelet transfusion during pregnancy and also find out the associated morbidity and mortality in mother and fetus. All the women who required platelet transfusion in peripartum period were included whereas the study by Parnas et al and Vyas et al included the women with moderate to severe thrombocytopenia however Dwivedi et al considered all women with thrombocytopenia. ${ }^{2-4}$

During the study period there were $11.2 \% \quad(n=884)$ women who had thrombocytopenia of total deliveries which is similar to the study Boehlen et al. ${ }^{5}$ But other study quoted the prevalence of thrombocytopenia ranging from $6-10 \%{ }^{1}$ Also in a study by Olayemi E et al the incidence of thrombocytopenia is almost $15.3 \%$ due to undiagnosed cases of malaria over there. ${ }^{6}$ Out of 884 women with thrombocytopenia, only 70 of them $(0.87 \%)$ required platelet transfusion which constituted the study group but 6 patients $(3 \%)$ required transfusion in the study by Parnas et al. ${ }^{2}$

The mean age of patient receiving platelet transfusion was 25.2 years which was similar the study by Dwivedi et al but lower than that reported by Wang DP et al and in Parnas et al of 29.4 years and 30.7 years respectively in their study population. ${ }^{2,47}$ It indicates early marriage and conception in the Indian subgroup.

Hypertensive disorder of pregnancy was the important etiology for platelet transfusion (37\%) whereas Vyas et al, Parnas et al and Dwivedi et al reported it to be a cause in $22 \%, 22.1 \%$ and $42.55 \%$ respectively. ${ }^{2-4}$ Anemia associated with thrombocytopenia was seen in $17.1 \%$ of subjects where Dwivedi et al found to be as high as $27.15 \%{ }^{4}$

India is an endemic zone for diseases like dengue, malaria and typhoid. Thrombocytopenia in pregnancy requiring platelet transfusion during peripartum period was attributed to $15.7 \%$

$(n=11)$ in the present study. The immediate obstetric complications in form of APH, PPH and rupture uterus was found in 19 women and were treated as per immediate obstetric management as well as vigorous transfusion. Only one woman had APLA and one had ITP. Women with ITP required platelet transfusion as she developed abruption which is similar to study by Parnas et al were one patient of ITP had transfusion. ${ }^{2}$

Maternal complication in form of operative intervention was as high as $50 \%$ in our study group but other reported $36.2 \%$ and $37.5 \%$. ${ }^{2,3}$ In our study group, 6 women had to undergo hysterectomy and 4 women expired but Parnas et al, Dwivedi et al, Vyas et al did not have any mortality. ${ }^{2-4}$ This is probably because our institute is a tertiary care referral centre and women would come generally in very terminal stages in emergency.

Women with thrombocytopenia are more likely to deliver preterm (less than 37 weeks) which is due to increase need for labor induction in face of obstetrical complications such as HELLP, abruption, etc associated with thrombocytopenia. Due to need of early induction by women with preeclampsia and HELLP, 29 preterm deliveries were seen. There were 13 IUD due to as women presented in shock or severe obstetric complication in form of rupture uterus or obstetrical hemorrhage. Nursery admission and care was required by 19 neonates of whom three expired. There were no bleeding tendencies in neonates of our study group as also in Parnas et al and Dwivedi et al. The complications in neonates were due to prematurity. None of the neonates had thrombocytopenia but Parnas et al and Dwivedi et al had it in $3.51 \%$ and $17.02 \%$ respectively. ${ }^{2,4}$ This is because majority of women had hypertensive disorder of pregnancy, infections and immediate obstetrical complications which does not lead to thrombocytopenia in neonates.

Limitation of the study included a small group of patients and the data is from single institute.

\section{CONCLUSION}

To conclude, severe thrombocytopenia is a marker of grave medical condition rather than a cause. Thus identification and timed management of these underline causes is important. Further studies are required to screen high risk population with thrombocytopenia to make the effective screening and management program.

\section{Funding: No funding sources \\ Conflict of interest: None declared \\ Ethical approval: Not required}

\section{REFERENCES}

1. McCrae KR. Thrombocytopenia in Pregnancy. Hematology. 2010;2010(1):397-402.

2. Parnas M, Sheiner E, Shoham-Vardi I, Burstein E, Yermiahu T, Levi I, et al. Moderate to severe thrombocytopenia during pregnancy. Eur J Obstet Gynecol Reprod Biol. 2006;128(1-2):163-8.

3. Vyas R, Shah S, Yadav P, Patel U. Comparative study of mild versus moderate to severe thrombocytopenia in third trimester of pregnancy in a tertiary care hospital. NHL Journal of Medical Sciences. 2014;3(1):8-11.

4. Dwivedi P, Puri M, Nigam A, Agarwal K. Fetomaternal outcome in pregnancy with severe thrombocytopenia. Eur Rev Med Pharmacol Sci. 2012;16(11):1563-6. 
5. Boehlen F, Hohlfeld P, Extermann P, Perneger TV, de Moerloose P. Platelet count at term pregnancy: a reappraisal of the threshold. Obstet Gynecol. 2000;95(1):29-33.

6. Olayemi E, Akuffo FW. Gestational thrombocytopenia among pregnant Ghanaian women. Pan Afr Med J. 2012;12:34.
7. Wang DP, Liang MY, Wang SM. Clinical analysis of pregnancy complicated with severe thrombocytopenia. Zhonghua $\mathrm{Fu}$ Chan KeZaZhi. 2010;45(6):401-5.

Cite this article as: Khatuja $\mathrm{R}$, Jain $\mathrm{G}$,

Radhakrishnan G, Grover A, Singh B. Platelet transfusion in pregnancy: clinical profile and pregnancy outcome. Int J Reprod Contracept Obstet Gynecol 2016;5:2200-3. 